\title{
Investigation of the effects of heat loss through below-grade envelope of buildings in urban areas on thermo-mechanical behaviour of geothermal piles
}

\author{
Maryam Saaly ${ }^{1, *}$, and Pooneh Maghoul ${ }^{1}$, Hartmut Holländer $^{1}$ \\ ${ }^{1}$ University of Manitoba, Civil Engineering Department, 15 Gillson St., Winnipeg, Canada
}

\begin{abstract}
Harvesting geothermal energy through the use of thermo-active pile systems is an eco-friendly technique to provide HVAC energy demand of buildings. Mechanical behaviour of thermo-active piles is impacted by thermal cycles. Moreover, in urban areas, the temperature of the ground is higher than nonconstructed areas due to the heat loss through the below-grade enclosure of buildings. This heat dissipation increases the thermal capacity of the soil and affects the mechanical response of the geothermal pile foundation subjected to thermo-mechanical loading. To investigate the effect of buildings heat loss on thermoactive piles, a numerical thermo-mechanical (TM) analysis was carried out on a proposed energy foundation system for an institutional building, the Stanley Pauley Engineering Building (SPEB) in the campus of the University of Manitoba, Winnipeg, Canada. The mechanical response of the geothermal piles to the thermal cycles with and without considering heat leakage through the basement of the SPEB is compared. Results showed that the cooling loads induced a maximum vertical pile head displacement of $-1.18 \mathrm{~mm}$. After 5 years operation of the system, the maximum vertical pile head displacement decreased to $-1.05 \mathrm{~mm}$ for the case in which heat loss through the basement in considered in the models. In addition, the maximum axial load effective along the pile axis was $6 \%$ higher for the case that considers heat loss through the basement compared to the case without considering heat leakage through the building's below-grade envelope.
\end{abstract}

\section{Introduction}

The energy consumption has increased all over the world due to the population growth and industrial needs. One of the alternatives to address this increasing energy demand is the application of geothermal energy using a rapidly growing construction technology, geothermal energy piles. Such a system integrates the geothermal energy technique into the structural pile foundation system [1].

The geothermal pile operation principle is based on circulation of a heat carrier fluid in polyethylene pipes embedded in the piles through which heat exchange occurs between the geothermal energy pile and the surrounding medium. This energy further feeds the Ground Source Heat Pump (GSHP) system so that the geothermal energy pile acts as heat exchangers in addition to their main function as structural support elements.

Geothermal piles are broadly applied in European countries [2], but in Canada, the application of such foundation systems is not well established and limited knowledge regarding the thermal and mechanical operation of them exists. For example, Laloui et al. [3] have carried out experimental tests on a full-scale pile within the foundation of a four story building in Lausanne, Switzerland. The tested pile was equipped with one Ushape probe for transferring heat. Based on the results, the effective axial load on the pile is impacted by the thermal cycles especially at the pile toe where the axial load can be twice as effective as only the mechanical loading stage. In another experimental work, Bourne-Webb et al. [2] conducted some in-situ tests on a single thermo-active pile installed in London Clay. The main scope of the in-situ tests was to evaluate the mechanical performance of the pile subjected to thermal cycles. The temperature and strain profiles of the tested pile were recorded using an optical sensor system, vibrating-wire strain gauges, thermistors, and external load control elements. Based on the obtained results, temperature changes in the pile, depending on whether the pile is heated or cooled, changed the mobilized shaft friction along the pile-soil interface. It was speculated that if the margin between the pile ultimate shaft resistance and shaft friction along the soil-pile interface is large enough, the pile capacity will not change significantly.

Efforts for the application of energy foundations have recently been expanded in North America. For example, Akrouch et al. [4] carried out an experimental study on the time dependent thermo-mechanical (TM) behaviour of a single geothermal energy pile which was installed and instrumented at the campus of the Texas A\&M University. One of the important remarks of this study was that the soil properties at the construction site, which included very stiff high plasticity clay in which the creep rate might be an important parameter to consider. The

\footnotetext{
*Corresponding Author: Pooneh.Maghoul@umanitoba.ca
} 
obtained results confirmed that the increase in soil temperature due to the operation of the pile during the cooling mode (heat injection to the ground during summers) increased the creep rate of clay which correspondingly caused the increase in long-term displacement of the pile. Therefore, the application of the thermo-active pile that was installed in highly plastic clay was not suggested for cooling dominated climates (i.e., warm regions).

Although broadly expanded in Europe and US, in Canada, the application of geothermal piles is not well established and limited knowledge regarding the thermal and mechanical operation of such systems exists. In Canada, the operation of GSHP systems may not be satisfactory and may degrade over a few years of the operation of geothermal energy piles. The reason for such malfunction is underground thermal imbalance, which is the term used for the gradual decrease in the ground temperature over years because of an excessive heat extraction for heating the space during the long winter season. As soil temperature decreases, the outlet temperature of the Ground Heat Exchanger (GHE) lowers gradually. This contributes to the deterioration of the heating performance of the GSHP. In addition, the underground thermal imbalance and excessive heat extraction can decrease the soil temperature below the freezing point. This causes freezing at the pile-soil interface which temporarily increases the bearing capacity of the geothermal energy pile. However, during spring, thawing occurs at the soil-pile interface, which decreases the bearing capacity of the piles significantly. The occurrence of such freezing and thawing cycles at the soilpile interface adversely affects the structural integrity as well as the energy efficiency of such systems [5]. Therefore, it is important to consider the potential occurrence of ground thermal imbalance, i.e. the energy performance, in the design of geothermal pile foundation systems in cold regions.

In urban areas, the ground temperature below the buildings base area is higher than open fields due to the heat dissipation of buildings through their sub-grade enclosures [6]. Such heat can further be re-harvested by a geothermal foundation system which favourably affects the efficiency of the GSHPs. Moreover, this additional dissipated heat from the building basement can ameliorate the potential thermal imbalance in the ground. In this regard, Saaly et al. [7] conducted a study to determine the thermal capacity of a proposed hypothetical geothermal foundation system considering the heat loss through the basement of an institutional building in cold regions.

The geothermal energy piles are subjected to both thermal loads due to temperature variations of the fluid heat exchanger whose magnitude is a function of the building heating and cooling demand as well as structural loads. Therefore, aside from the energy performance of the system, the impacts of thermal loading on the structural performance of geothermal piles should be assessed. For example, thermal loads cause volumetric expansion and contraction when piles are heated and cooled, respectively. In addition, the thermo-mechanical properties of soils surrounding the pile foundation are temperature-dependent, which can affect the interaction between the soil and foundation at their interface [8].

This paper is aimed to investigate the thermo-mechanical behaviour of a single pile in a geothermal energy foundation system, which is designed for energy supply of an institutional building in Winnipeg, Canada. This foundation system is subjected to heat dissipation through the below-grade enclosure of the building. The present work is intended to provide a tool for prediction of the thermo-mechanical response of energy piles by incorporating the knowledge of buildings energy loss.

\section{Geothermal Energy Foundation System}

The investigated geothermal energy foundation system belongs to a four story institutional building, the Stanley Pauley Engineering Building (SPEB) that is located in Winnipeg (MB), Canada. Buildings in Winnipeg typically have a high heating and cooling energy demand [9]. The reason is an average daily temperature fluctuations ranging from $+20^{\circ} \mathrm{C}$ in summer to $-20^{\circ} \mathrm{C}$ in winter.

Based on the reports of the geotechnical investigation conducted prior to construction of the building, the stratigraphy of the site consists of a layer of dark grey clay deposits having a thickness of $2 \mathrm{~m}$ overlaying a $14.7 \mathrm{~m}$ thick layer of brown clay followed by a dense layer of till deposits.

The building foundation of consists of 119 concrete micro-piles designed for an ultimate limit state axial resistance of $1000 \mathrm{kN}$, which are embedded at the depth of $-4.25 \mathrm{~m}$ below grade. Saaly et al. [7] proposed a geothermal foundation system in which all the 119 piles were considered to be geothermal energy piles and were equipped with heat exchanger pipes to supply the SBEB energy demand (Fig. 1).

The inlet temperature of fluid in the heat exchanger pipes varies between $-1{ }^{\circ} \mathrm{C}$ during Nov-Apr and $20^{\circ} \mathrm{C}$ during May-Oct, and has been determined to meet two main criteria: (i) meeting the thermal balance of the ground during heat extraction and rejection, (ii) avoiding freezing at the soil-pile interface [7]. Based on the results, up to $41 \%$ of the energy demand of the Stanley Pauley building can be supplied using a geothermal energy pile foundation system while meeting the two mentioned criteria [7]. Since temperature variation in the probes impacts the mechanical behaviour of the piles, the mechanical behaviour of a single geothermal pile in the foundation system of the SPEB is aimed to be studied in the following sections. 


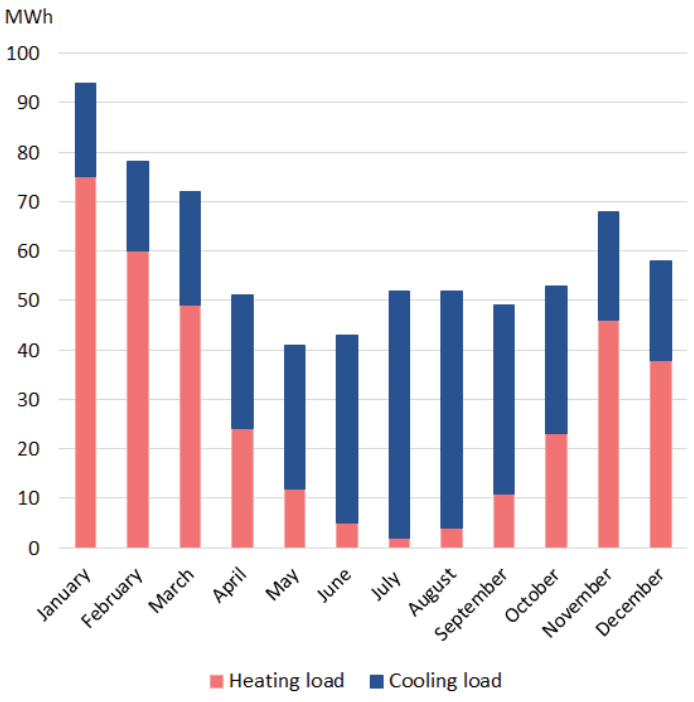

Fig. 1. Monthly heating and cooling energy demand of the Stanley Pauley Engineering Building [9].

\section{Thermo-Mechanical (TM) Model}

\subsection{Governing Equations}

A coupled thermo-mechanical model has been developed to assess the mechanical and thermal behaviours of one of the geothermal piles of the SPEB foundation system which is based on the following assumption: (a) Soil is taken to be fully-saturated having two-phases (solid skeleton and water). The soil is modelled as an isotropic, elastoplastic material. The Mohr-Coulomb constitutive model is used to determine the size of the yield surface in the soil. (b) Pile material is considered to be solid, isotropic and linear elastic. (c) Perfect contact has been assumed at the interface between the soil and pile.

Considering the above-mentioned assumptions, the set of governing equations proposed by Laloui et al. [3] are applied in the present analysis:

$$
\begin{aligned}
& \nabla . \boldsymbol{\sigma}+\boldsymbol{b}=0 \\
& \boldsymbol{b}=\rho \boldsymbol{g}
\end{aligned}
$$

where $\nabla$. is the divergence operator, $\boldsymbol{\sigma}$ is the total (Cauchy) stress tensor, $\boldsymbol{b}$ is the body force vector, $\boldsymbol{g}$ is the gravitational acceleration vector, and $\rho$ is the average bulk density of the soil that can be determined as below:

$$
\rho=(1+n) \rho_{s}+n \rho_{w}
$$

where, $\rho_{s}$ and $\rho_{w}$ are the density of solid skeleton and water, respectively. Also, $n$ is the porosity of the soil. The constitutive law describing the stress-strain relations is defined in terms of the effective stress as below:

$$
\begin{aligned}
\boldsymbol{\sigma} & =\boldsymbol{D}\left(\varepsilon-\varepsilon^{T}-\varepsilon^{p l}\right) \\
\varepsilon^{T} & =\frac{1}{3}\left(\alpha_{s} \nabla T\right)
\end{aligned}
$$

where $\boldsymbol{D}$ is the stiffness tensor, $\varepsilon$ is the strain tensor, $\varepsilon^{T}$ is the thermal strain tensor, and $\varepsilon^{p l}$ is the plastic strain tensor. Plastic strains are computed by the Mohr-Coulomb yield criterion. $\alpha_{s}$ is the volumetric thermal expansion coefficient, $\nabla$ is the gradient operator, and $T$ stands for the temperature.

To determine the heat transfer in porous media, the following equations are applied:

$$
\begin{aligned}
& \rho C \frac{\partial T}{\partial t}+\nabla \cdot q_{c}=0 \\
& \rho C=(1-n) \rho_{s} C_{s}+n \rho_{w} C_{w} \\
& q_{c}=-\lambda \nabla T \\
& \lambda=(1-n) \lambda_{s}+n \lambda_{w}
\end{aligned}
$$

where $\rho C$ is the volumetric heat capacity of the soil which is a function of volumetric heat capacity of solid skeleton $\left(\rho_{s} C_{s}\right)$ and pore water $\left(\rho_{w} C_{w}\right), q_{c}$ is the conductive heat flux through the volume which is defined by Fourier's law, $\lambda$ denotes the effective thermal conductivity of the material whose value for the soil depends on $\lambda_{s}$ is thermal conductivity of solid grains and $\lambda_{w}$ is thermal conductivity of water.

The time-dependent numerical model has been implemented in the finite-element commercial software COMSOL Multiphysics. The dimension of the 2D axisymmetric model applied in this study is $10 \mathrm{~m} \times 10 \mathrm{~m}$. On top of the soil domain, a $0.23 \mathrm{~m}$ thick layer of thermal insulation and a $0.2 \mathrm{~m}$ thick layer of concrete slab are placed (Fig. 2). The modelled pile is a friction pile having $0.4 \mathrm{~m}$ diameter and a length of $5 \mathrm{~m}$. The thermomechanical properties of the materials used in the model are summarized in Table 1.

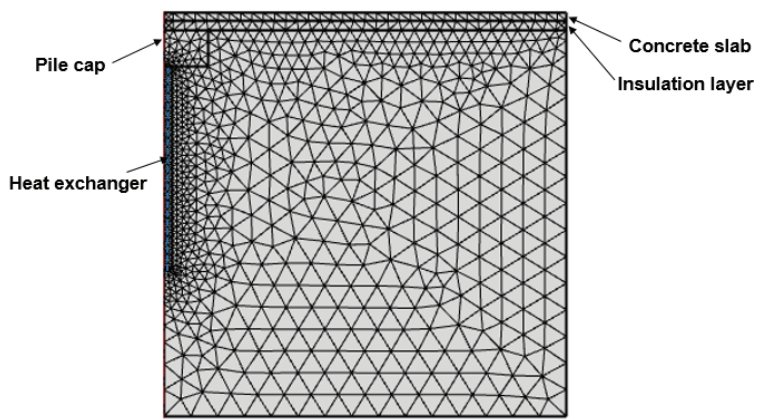

Fig. 2. Axisymmetric finite elements model. 
Table 1. Properties of SPEB's numerical model.

\begin{tabular}{|c|c|c|c|}
\hline $\begin{array}{c}\text { Young's modulus } \\
(\mathrm{Pa})\end{array}$ & $70 \times 10^{6}$ & $40 \times 10^{9}$ & - \\
\hline Poisson ratio (-) & 0.236 & 0.2 & - \\
\hline Density $\left(\mathrm{kg} / \mathrm{m}^{3}\right)$ & 1767 & 2300 & 34 \\
\hline $\begin{array}{c}\text { Thermal conductivity } \\
\left(\mathrm{W} / \mathrm{m}^{\circ} \mathrm{C}\right)\end{array}$ & 1.483 & 1.5 & 0.041 \\
\hline $\begin{array}{c}\text { Specific heat capacity } \\
\left(\mathrm{J} / \mathrm{kg}^{\circ} \mathrm{C}\right)\end{array}$ & 960 & 880 & 1450 \\
\hline $\begin{array}{c}\text { Thermal expansion } \\
\text { coefficient }(1 / \mathrm{K})\end{array}$ & $1.7 \times 10^{-5}$ & $8.5 \times 10^{-6}$ & - \\
\hline $\begin{array}{c}\text { Porosity }(-) \\
\text { Cohesion }(\mathrm{kPa})\end{array}$ & 0.535 & - & - \\
\hline Friction angle $\left({ }^{\circ}\right)$ & 18 & - & - \\
\hline
\end{tabular}

The boundary conditions of the thermo-mechanical (TM) model are as follows:

- The thermal boundary conditions: constant temperature on the heat exchanger, adiabatic condition at the bottom and surrounding boundaries are considered. Also, to estimate the impacts of heat dissipation through the building basement slab, a convective heat flux $q_{0}$ is assigned to the top boundary of the model as follows:

$$
q_{0}=h\left(T_{\text {indoor }}-T_{s}\right)
$$

where $h$ is the convective heat transfer coefficient whose value is assumed to be equal to $6 \mathrm{~W} / \mathrm{m}^{2 \circ} \mathrm{C}[5], T_{\text {indoor }}$ is the basement indoor air temperature that is assumed constant and equal to $20^{\circ} \mathrm{C}, T_{s}$ is the temperature at the ground surface.

- The mechanical boundary conditions: the roller condition on the right boundary of the model, and fixed constraint at the bottom of the domain are considered. An axisymmetric condition is assumed from the left boundary.

The initial temperature of the model is assumed to be equal to $8^{\circ} \mathrm{C}$ [7]. Also, the initial stress conditions are obtained from the results of another steady-state simulation considering only the gravity effects. In other words, the finite element analysis has been done in two stages. Through the first stage, a steady state analysis has been carried out while considering the gravity effects to generate the initial stresses as the input for the transient simulation. In the transient stage, the energy pile response to the applied axial load and thermal cycles has been studied over a five-year span of time.

\subsection{Model Validation}

The model has been validated against experimental data provided by Bourne-Webb et al. [2]. The experimental data has been obtained from a test pile that was equipped with the heat exchanger pipes. Fig. 3 shows the thermo- mechanical loading applied on the tested pile in BourneWebb et al. study.

Comparing the pile head displacements obtained from the experimental tests and the numerical model, good agreement was found during the cooling phase (100 - 860 h) (Fig. 4). Although the magnitude of vertical displacement of the pile head during the heating loading is slightly lower in the numerical model, the similarities are acceptable from an engineering point of view to consider the model an appropriate tool for predicting the thermo-mechanical behaviour of the thermal pile.

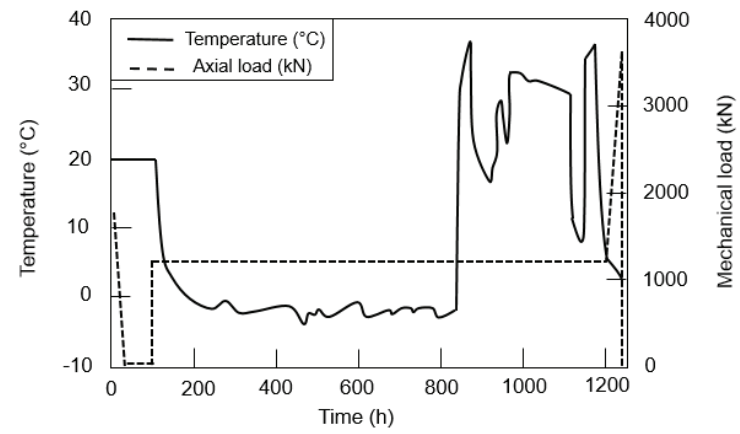

Fig. 3. Thermo-mechanical loading history of experimental case (after Bourne-Webb et al. [2]).

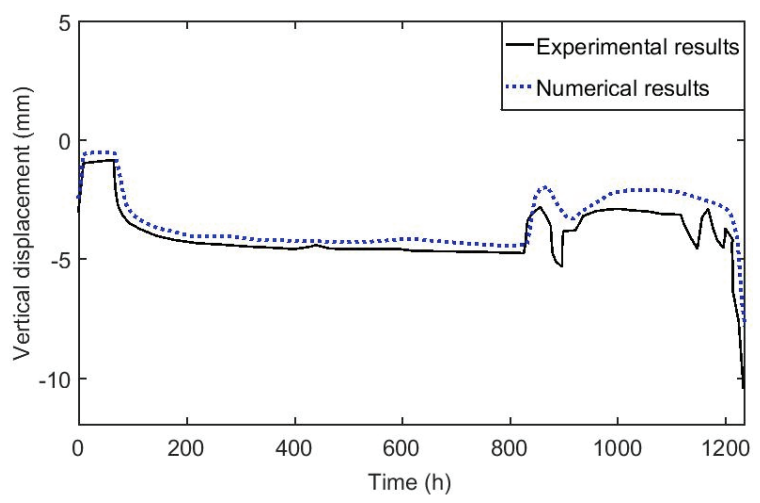

Fig. 4. Comparison between the numerical and field data regarding the vertical displacement of the pile head.

\subsection{Thermo-Mechanical Loading History of the Geothermal Energy Pile in SPEB}

The validated numerical model in COMSOL Multiphysics is applied to study the behaviour of one of the geothermal piles of the SPEB's foundation. The total loading time was 1825 days (five years) which included 6 months heating and 6 month cooling per year in addition to a constant mechanical load equal to the ultimate capacity of the friction pile (i.e. $1000 \mathrm{kN}$ ) that is applied with a factor of safety of 3.0. In this work, the thermal load is represented by a constant temperature, which is equal to the inlet temperature of the heat exchanger fluid, along the length of the heat exchanger pipe. Based on the numerical study carried out by Saaly et al. [7] the inlet temperatures of the pipe were suggested to be equal to $20^{\circ} \mathrm{C}$ during May-Oct and $-1^{\circ} \mathrm{C}$ during the 6 Nov-Apr of each year. As mentioned before, the inlet temperatures 
were chosen to meet the thermal balance of the ground during over the year as well as to avoid freezing at the soil-pile interface. Fig. 5 provides the seasonal variation of the inlet temperature of the heat carrier fluid as well as the mechanical load applied to the head of the pile.

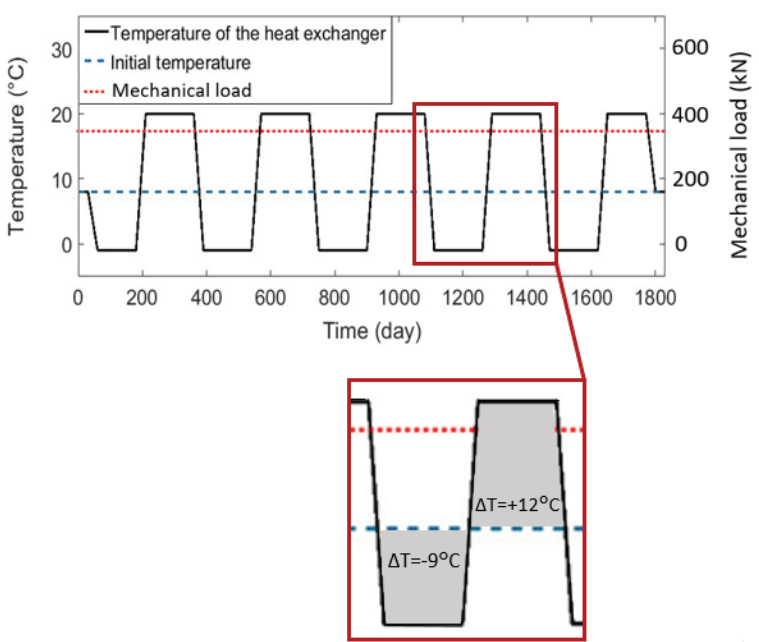

Fig. 5. Time histories of applied thermal and mechanical loads.

To demonstrate the initial pile settlement due to only the mechanical load, during the first 30 days of the simulation the temperature in the probes is equal to the initial temperature $\left(\mathrm{T}_{\text {initial }}=8^{\circ} \mathrm{C}\right)$. In addition, during the last 30 days of the loading time history, the temperature of the probes are equal to $8^{\circ} \mathrm{C}$ to evaluate the reversibility of pile head displacement induced by the thermal loads.

\section{Results and Discussion}

The pile head displacements and the maximum axial load induced by the thermo-mechanical loads are investigated in this section. The reason is that such factors are considered in the Limit State-based geotechnical design. The thermo-active pile and its surrounding soils were subjected to an additional thermal load due to the heat loss through the slab of the basement floor. Such heat dissipation from the basement into the ground occurred in spite of insulating the basement envelope.

The initial pile head displacement that was induced by the mechanical load at the end of the first 30 days of the simulation time history was equal to $-0.79 \mathrm{~mm}$ (Fig. 6 ). Once heat extraction from the ground by applying a $\Delta \mathrm{T}=-9^{\circ} \mathrm{C}$ began, further pile head displacement occurred whose maximum reached to $-1.19 \mathrm{~mm}$ at $\mathrm{t}=182$ days for the case with heat loss through basement (Case 1). For the case with no heat loss through the basement (Case 2), the minimum pile head displacement reached $-1.18 \mathrm{~mm}$ at $\mathrm{t}=$ 182 days. This means that during the first few months of the analysis, the heat loss through the slab was not effective enough to influence the pile head displacement. This could be because of the significant thermal mass of the ground in the short time.

In contrast, during the heating loading (May-Oct), the geothermal pile expanded upon a $+12^{\circ} \mathrm{C}$ temperature increase. The maximum expansion, whose value was
$+0.43 \mathrm{~mm}$ relative to the initial settlement, happened at $\mathrm{t}$ $=1795$ days (i.e., the end of the cooling season of the fifth year of analysis). However, without considering the energy loss from the slab (Case 1), the maximum expansion reached to $+0.31 \mathrm{~mm}$ which showed occurrence of $15 \%$ less expansion compared to the maximum expansion of the pile head in Case 2. This discrepancy was due to heat leakage through the basement which increased the soil temperature near the basement floor.

During the last 30 days of the operation of the system (i.e. at the end of the fifth year; 1795-1825 days), the inlet temperature of the pipes was set equal to the initial temperature of the pile $\left(\mathrm{T}_{\text {initial }}=8^{\circ} \mathrm{C}\right)$ to evaluate the reversibility of displacement induced by the thermal loads. It was observed that $40 \%$ and $25 \%$ of the initial pile head displacement left in the pile for the cases with and without considering heat loss, respectively. This happens due to the elastoplastic behaviour of the soil. In addition, for the case in which the basement energy loss was taken into account, the soil temperature increased up to $1.5^{\circ} \mathrm{C}$ near the basement floor. Therefore, a larger residual displacement was observed for this case.

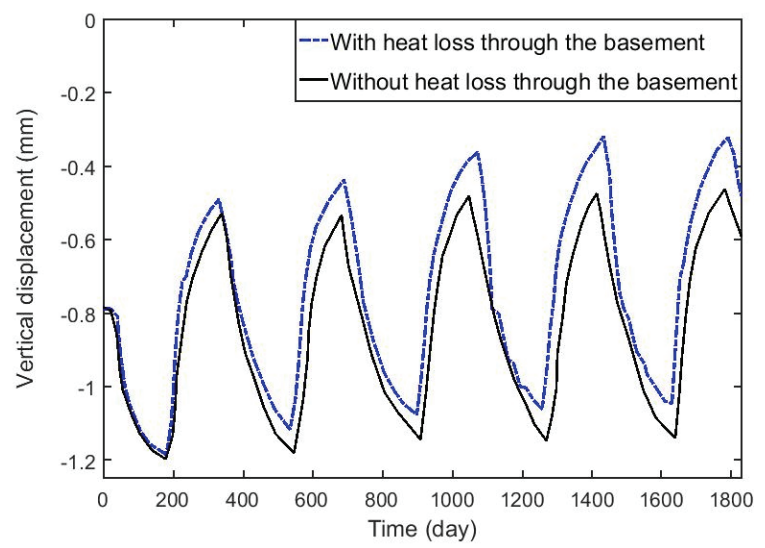

Fig. 6. Vertical displacement of the pile head with and without consideration of the heat leakage from the SPEB basement.

In Case 1, in the stage in which the pile was subjected to only mechanical load, the pile was fully compressed. However, when a cooling load was applied in addition to the mechanical load to extract heat from the ground $(\Delta \mathrm{T}$ $\left.=0^{\circ} \mathrm{C}\right)$, the concrete pile contracted. Pile contraction induced tensile forces in the pile. Therefore, the axial load along the pile length decreased compared to the only mechanical loading stage. The maximum reduction in axial load that was applied on the pile due to the cooling load is $28 \mathrm{kPa}$ (i.e., $9 \%$ reduction in the axial load during cooling stage loading compared to mechanical loading stage) that occurred at $0.9 \mathrm{~m}$ below the pile head (Fig. 7). According to the results regarding the axial load along the pile axis for Case 2, at the end of heating loading stage, the pile was up to $9 \%$ more compressed compared to the initial mechanical load applied on the pile (i.e., $333 \mathrm{kN}$ ) (Fig. 7). It was observed that the maximum compressive load in Case 2, which was equal to $363 \mathrm{kN}$, was induced at the pile depth of $0.6 \mathrm{~m}$ during the heating loading stage. While the maximum axial load that was induced during 
heating loading at the same pile depth in Case 1 was 342 $\mathrm{kN}$ which was $6 \%$ lower than the maximum axial load in Case 2. The reason was the additional pile expansion in Case 2 due to the heat loss through the basement. Such results signify that considering the buildings heat leakage through the underground enclosure in urban areas may be an important factor in assessing the geothermal energy pile response to thermo-mechanical loading.

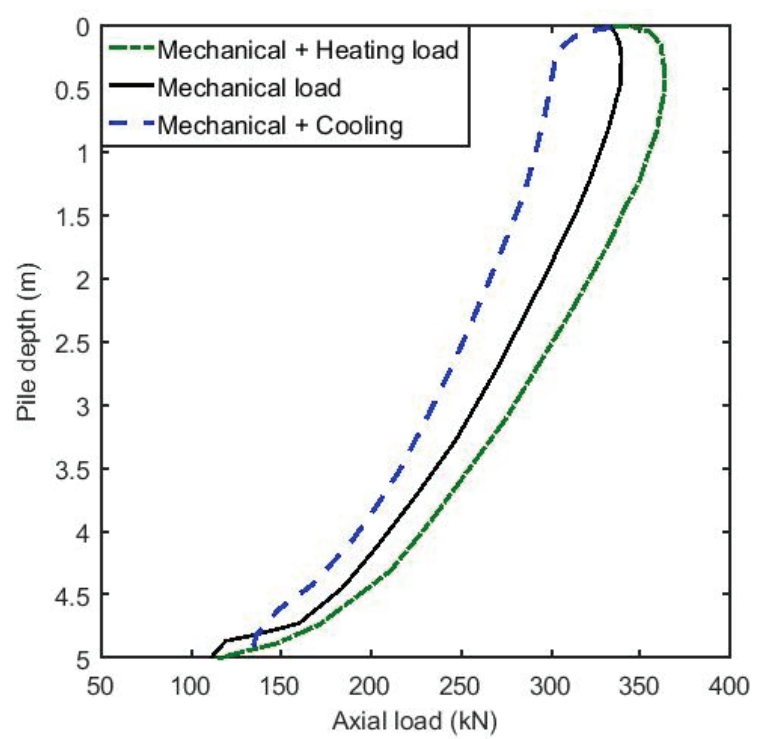

Fig. 6. Axial load distribution along the pile axis.

The axial load distribution illustrated in Fig. 6 signified that the thermal cycles change the magnitude of the induced axial load along the pile. In other words, the heating load (i.e., $\Delta \mathrm{T}=12^{\circ} \mathrm{C}$ ) increased the induced axial load along the pile up to $9 \%$. Such an increase in the axial load along the pile should be addressed in the geotechnical design by considering a higher factor of safety. For example, in Case 2 that the obtained maximum compressive axial load along the pile axis was $363 \mathrm{kN}$, $9 \%$ increase in the factor of safety (initially considered to be equal to 3.0) is required to ensure safe application of the thermo-active pile since the pile was initially designed for allowable load of $333 \mathrm{kN}$. In practice, a factor of safety of 3.5 fulfils the required safety margin for the pile that is studied in this work.

\section{Conclusion}

The results verified that when the energy pile was subjected to heating and cooling loads, the thermal deformations generated additional compressive and tensile stresses during heating stage and cooling stage, respectively. This necessitates further considerations such as increasing the factor of safety effective on the allowable load. Also, during the cooling stage, the pile head downward displacement increased due to pile contraction which was in admissible limit according to the National Building Code of Canada. In addition, the obtained results showed the importance of considering heat dissipation through the basement in evaluating the thermo-mechanical behaviour of geothermal energy piles.

\section{References}

1. J. Fadejev, J. Kurnitski, Y. Chen, Energy Build., Geothermal energy piles and boreholes design with heat pump in a whole building simulation software, Energy and Buildings 106, 23-24 (2015).

2. P.J. Bourne-Webb, B. Amatya, K. Soga, T. Amis T, C. Davidson, P. Payne, Geotechnique, Energy pile test at lambeth college, london: geotechncial and thermo-dynamic aspects of pile response to heat cycles, Géotechnique 3, 237-248 (2009).

3. L. Laloui, M. Nuth, L. Vuliet, Int. J. Numer. Anal. Methods Geomech., Experimental and numerical investigations of the behaviour of a heat exchanger pile, International Journal for Numerical and Analytical Methods in Geomechanics 30, 763-781 (2006).

4. G. A. Akrouch, M. Sanchez, J.L. Briaud, Acta Geotechnica, Thermo-mechanical behavior of energy piles in high plasticity clays, Acta Geotechnica 9, 399-412 (2014).

5. H. Liu, P. Maghoul, A. Bahari, M. Kavgic, Renew. Energy, Feasibility study of snow melting system using geothermal energy heat pumps in Canada, Renewable Energy 136, (2019).

6. A. Fergusen A, A.D. Woodbury, J. Geophys. Res., Subsurface heat flow in an urban environment, Journal of Geophysical Research 109, 1-9 (2004).

7. M. Saaly, P. Maghoul, M. Kavgic, D. Polyzois, Sustain. Cities Soc., Performance analysis of a proposed geothermal pile system for heating and cooling energy demand for a building in cold regions, Sustainable Cities and Societies 45, 669-682 (2019).

8. C. Cekerevac, L. Laloui, Int. J. Numer. Anal. Methods Geomech., Experimental study of thermal effects on the mechanical behavior of a clay, International Journal of Numerical Methods in Geomechanics 28, 209-228 (2004).

9. A. Al-Janabi, M. Kavgic, A. Mohammadzadeh, A. Azzouz, J. Build. Eng., Comparison of energyplus and IES to model a complex university building using three scenarios : Free-floating, ideal air load system, and detailed, Journal of Building Engineering 22, 262-280 (2019). 